\title{
Mycoplasma genitalium Antimicrobial Resistance in Community and Sexual Health Clinic Patients, Auckland, New Zealand
}

\author{
Anna Vesty, Gary McAuliffe, Sally Roberts, Gillian Henderson, Indira Basu
}

Our retrospective study compared genotypic antimicrobial resistance in Mycoplasma genitalium-positive specimens collected from 48 community and 33 sexual health clinic (SHC) patients. Macrolide resistance was similar in community (75\%) and SHC (76\%) patients. We observed no significant difference in fluoroquinolone resistance between community (19\%) and SHC (27\%) patients $(p=0.66)$.

M anagement of Mycoplasma genitalium infections is challenging because the limited treatment options have been affected by rapidly evolving resistance to antimicrobial drugs. Molecular approaches are the preferred method of M. genitalium detection, and resistance is determined genotypically. $23 \mathrm{~S}$ rRNA mutations are associated with macrolide resistance and azithromycin treatment failures (1-3), whereas fluoroquinolone resistance is associated with mutations in the quinolone resistance-determining region, specifically in the gyrA and parC genes (4).

Azithromycin is the first-line treatment for $M$. genitalium infections in New Zealand; second-line treatment relies on moxifloxacin, a fluoroquinolone. A high proportion $(72 \%)$ of macrolide resistance has been reported in sexual health clinic (SHC) patients in our region (5), and elsewhere in New Zealand fluoroquinolone resistance is reported in $23.3 \%$ of $M$. genitalium-positive specimens from SHC attendees (3), consistent with the high prevalence of macrolide and fluoroquinolone resistance in the Asia-Pacific region $(1,3,6)$.

Author affiliations: Auckland City Hospital, Auckland, New Zealand (A. Vesty, G. McAuliffe, S. Roberts, G. Henderson, I. Basu); Labtests, Auckland (G. McAuliffe)

DOI: https://doi.org/10.3201/eid2602.190533

\section{The Study}

We performed a retrospective study of all specimens referred to the Microbiology Department at Auckland City Hospital (Auckland, New Zealand) for $M$. genitalium testing in 2017. Referral sites were predominantly general practices in Auckland and SHCs in the Auckland, Northland, and Waikato regions. Ethics approval was granted by the Health and Disability Ethics Committee (approval no. 16/CEN/188).

DNA had been extracted from specimens following a diagnostic workflow and stored at $-80^{\circ} \mathrm{C}$. We retrieved DNA samples that tested positive for $M$. genitalium using real-time PCR $(5,7)$ for this study. We detected 23S rRNA mutations at nucleotide positions 2058 and 2059 (Escherichia coli numbering) by using the commercially available PlexPCR kit Resistance Plus MG (SpeeDx, https:/ / plexpcr.com) (5) and gyrA and $\operatorname{par} C$ mutations by using PCR amplification of $M$. genitalium nucleotides 172-402 of gyrA and 164-483 of parC (8), followed by sequencing on the Applied Biosystems 3130xl sequencer (Life Technologies, https://www.thermofisher.com). Sequences were aligned against $M$. genitalium reference genes (GenBank accession nos. CP003773 for gyrA and parC for U25549) by using SeqMan II (DNASTAR, https:// www.dnastar.com) and the mutations reported by using M. genitalium numbering. We compared prevalence of resistance-associated mutations in community and SHC cohorts by using a $\chi^{2}$ test $(\alpha=5 \%)$.

We tested 302 clinical specimens from 247 patients; 33\% (101/302) of samples from 34\% (84/247) of patients were M. genitalium DNA-positive. Four samples from 3 patients were excluded from subsequent analyses because insufficient PCR products were obtained for sequencing. We used the remaining 97 
Table 1. Prevalence of antimicrobial resistance in Mycoplasma genitalium strains from community and SHC patients, Auckland, New Zealand, 2017*

\begin{tabular}{|c|c|c|c|c|c|c|}
\hline \multirow[b]{3}{*}{ Genotypic-resistance profile } & \multirow{2}{*}{\multicolumn{3}{|c|}{ Mutation }} & \multicolumn{3}{|c|}{ Frequency, \% } \\
\hline & & & & \multirow{2}{*}{$\begin{array}{l}\text { Community } \\
\text { patients }\end{array}$} & \multirow{2}{*}{$\begin{array}{c}\text { SHC } \\
\text { patients }\end{array}$} & \multirow[b]{2}{*}{ All patients } \\
\hline & 23S rRNA & parC & gyrA & & & \\
\hline Wild type & - & - & - & 20.8 & 24.2 & 22.2 \\
\hline Macrolide & + & - & - & 60.4 & 48.5 & 55.6 \\
\hline Macrolide + fluoroquinolone & + & + & - & 12.5 & 12.1 & 12.3 \\
\hline Macrolide + fluoroquinolone & + & + & + & 2.1 & 15.1 & 7.4 \\
\hline Fluoroquinolone & - & + & - & 4.2 & 0 & 2.5 \\
\hline
\end{tabular}

M. genitalium DNA-positive samples obtained from 81 patients to determine macrolide and fluoroquinolone resistance. Specimens were urine samples (92\%) or urogenital swabs. The mean $( \pm \mathrm{SD})$ age of patients was $29( \pm 7.5)$ years, and $80 \%(65 / 81)$ of patients were men; $59 \%$ (48/81) were community patients, and $41 \%$ $(33 / 81)$ were SHC patients.

We detected macrolide mutations in 75\% (61/81) of patients (Table 1). We observed no significant difference in the prevalence of macrolide resistance between community $(75 \%[36 / 48])$ and SHC $(76 \%$ [25/33]) patients $(p=1.00)$. Fluoroquinolone-resistant strains of $M$. genitalium were identified in $22 \%(18 / 81)$ of patients on the basis of the presence of mutations previously associated with phenotypic antimicrobial resistance or treatment failure (Table 2). We observed no significant difference in proportions of fluoroquinolone resistance between community (19\% [9/48]) and SHC $(27 \%$ [9/33]) patients $(\mathrm{p}=0.66)$.

Missense mutations in $\operatorname{parC}$ at amino acid positions 81,83 , or 87 conferred fluoroquinolone resistance (Table 2). Mutations in codon 83 of parC are associated with resistance; therefore, the mutation at T249A was presumed to confer fluoroquinolone resistance. The importance of polymorphisms in parC at $\mathrm{C} 184 \mathrm{~T}$ and $\mathrm{C} 356 \mathrm{~T}$ is uncertain. Mutations in gyrA at codon 95 were detected in 6 patients, 5 of whom were
SHC attendees. All 6 patients harbored concomitant parC mutations that are associated with fluoroquinolone resistance, meaning that mutations in gyrA were not detected in the absence of parC mutations. The 5 patients with mutations in gyrA at G285A harbored a concurrent parC mutation at G248T, suggesting the strains were similar.

We detected dual macrolide and fluoroquinolone resistance in $20 \%(16 / 81)$ of patients (Table 1$)$. Fluoroquinolone-resistant strains were likely to show concurrent macrolide resistance $(89 \%)$, with the exception of strains from 2 community patients, which harbored only a fluoroquinolone resistance-associated mutation at codon 83 in parC.

Repeat specimens from 2 community patients were suggestive of macrolide resistance developing during the sampling period. For 1 patient, 2 of 3 urine samples received at 2 -month intervals were negative for $23 S$ rRNA mutations, with a mutation only detected in the most recent of the 3 samples. Another community patient was infected with a strain that harbored a parC mutation in codon 83 only; however, a $23 \mathrm{~S}$ rRNA mutation was later detected in 2 subsequent urine samples collected at 1-month intervals, and the parC mutation persisted. A SHC attendee harbored both $23 \mathrm{~S}$ rRNA and parC resistance-associated mutations initially, and a subsequent sample collected 5

\begin{tabular}{|c|c|c|c|c|c|}
\hline \multirow[b]{2}{*}{ Gene and mutation $\dagger$} & \multirow[b]{2}{*}{ Amino acid change } & \multicolumn{4}{|c|}{ No. patients with mutation } \\
\hline & & Community patients & SHC patients & All patients & References \\
\hline \multicolumn{6}{|l|}{ gyrA } \\
\hline G285A & Met $\rightarrow$ Ile (95) & 1 & 4 & 5 & $(1,9)$ \\
\hline G285T & Met $\rightarrow$ Ile (95) & 0 & 1 & 1 & (11) \\
\hline \multicolumn{6}{|l|}{ parC } \\
\hline C184T $\ddagger$ & Pro $\rightarrow$ Ser (61) & 3 & 2 & 5 & $(1,9,11)$ \\
\hline G241T & Gly $\rightarrow$ Cys (81) & 1 & 0 & 1 & $(1,12)$ \\
\hline A247C & Ser $\rightarrow \operatorname{Arg}(83)$ & 1 & 0 & 1 & $(1,3,9,12)$ \\
\hline G248T & Ser $\rightarrow$ Ile (83) & 2 & 6 & 8 & $(1-3,9)$ \\
\hline T249A & Ser $\rightarrow$ Arg (83) & 1 & 0 & 1 & \\
\hline G259A & Asp $\rightarrow$ Asn (87) & 2 & 0 & 2 & $(1-3,8,9,11)$ \\
\hline G259T & Asp $\rightarrow$ Tyr (87) & 2 & 3 & 5 & $(1,2,8,10)$ \\
\hline С356T $\ddagger$ & Ala $\rightarrow$ Val (119) & 1 & 0 & 1 & (11) \\
\hline
\end{tabular}

*Nucleotide position and amino acid changes shown are based on M. genitalium numbering. SHC, sexual health clinic. 
months later harbored a mutation in gyrA at G285T in addition to the $23 \mathrm{~S}$ rRNA and parC mutations.

\section{Conclusions}

Our findings imply that resistance is common in circulating M. genitalium stains in the general population and highlight the limited and declining antimicrobial options for treatment. Few studies have delineated antimicrobial resistance by referrer type, and our results imply that macrolide- and fluoroquinolone-resistant strains are endemic in sexual networks in the general population, rather than confined to, or disproportionately affecting, persons attending SHCs. This information might be useful at local and national levels for informing sexual health treatment guidelines, but a need exists for supranational monitoring and reporting of resistance, given that it varies between countries (13).

Infections caused by strains resistant to both macrolides and fluoroquinolones occurred in $20 \%$ of patients, who would require alternative treatment options to obtain clinical and microbiological cure. Although pristinamycin has been successfully used to treat patients with multidrug-resistant infections (14), this treatment is not publicly funded in New Zealand and is only available as an imported medicine by special approval, underscoring the importance of exploring new treatment strategies to manage patients with resistant strains.

The presence of fluoroquinolone resistance in macrolide-sensitive strains in the community is concerning and might signify emergence of circulating fluoroquinolone-monoresistant strains in the region, with consequent implications for future treatment strategies. Although our data do not distinguish between descendants of clonal mutant lineages and de novo variants, we speculate that the introduction of a resistant clone from overseas is likely and that the use of fluoroquinolones in the community contributes to selective pressure for resistant strains.

A limitation of this study was that we did not have patient information regarding treatment of infection or clinical outcomes. This information might help establish whether resistance developed during treatment or occurred through reinfection with a more resistant strain. Another limitation was the inability to establish chain of transmission between patients, which was particularly relevant to the 4 SHC attendees and 1 community patient who harbored similar strains with identical mutations in both the gyrA and parC genes.

Mutations in the gyrB and parE genes act synergistically to increase fluoroquinolone resistance when detected with mutations in gyrA, parC, or both and might also warrant consideration when screening strains for markers of resistance (15). We found that in genotypically fluoroquinolone-resistant strains, single-nucleotide polymorphisms in gyrA were only detected with concomitant parC mutations. This finding might support diagnostic laboratories in efforts to target only the 23S rRNA and parC genes during their genotypic-resistance testing.

Funding was provided by an Auckland District Health Board Charitable Trust grant (research project no. $A+7436)$.

\section{About the Author}

Ms. Vesty is a scientific officer at Auckland City Hospital and a PhD candidate at the University of Auckland, New Zealand. Her research interests include medical microbiology and the human microbiome.

\section{References}

1. Tagg KA, Jeoffreys NJ, Couldwell DL, Donald JA, Gilbert GL. Fluoroquinolone and macrolide resistanceassociated mutations in Mycoplasma genitalium. J Clin Microbiol. 2013;51:2245-9. PubMed https://doi.org/ 10.1128/JCM.00495-13

2. Couldwell DL, Tagg KA, Jeoffreys NJ, Gilbert GL. Failure of moxifloxacin treatment in Mycoplasma genitalium infections due to macrolide and fluoroquinolone resistance. Int J STD AIDS. 2013;24:822-8. https:/ / doi.org/ 10.1177/0956462413502008

3. Anderson T, Coughlan E, Werno A. Mycoplasma genitalium macrolide and fluoroquinolone resistance detection and clinical implications in a selected cohort in New Zealand. J Clin Microbiol. 2017;55:3242-8. https:/ / doi.org/10.1128/ JCM.01087-17

4. Yamaguchi Y, Takei M, Kishii R, Yasuda M, Deguchi T. Contribution of topoisomerase IV mutation to quinolone resistance in Mycoplasma genitalium. Antimicrob Agents Chemother. 2013;57:1772-6. https:/ / doi.org/10.1128/ AAC.01956-12

5. Basu I, Roberts SA, Bower JE, Henderson G, Reid M. High macrolide resistance in Mycoplasma genitalium strains causing infection in Auckland, New Zealand. J Clin Microbiol. 2017;55:2280-2. https://doi.org/10.1128/ JCM.00370-17

6. Kikuchi M, Ito S, Yasuda M, Tsuchiya T, Hatazaki K, Takanashi M, et al. Remarkable increase in fluoroquinoloneresistant Mycoplasma genitalium in Japan. J Antimicrob Chemother. 2014;69:2376-82. https://doi.org/10.1093/jac/ dku164

7. Jensen JS, Björnelius E, Dohn B, Lidbrink P. Use of TaqMan 5 ' nuclease real-time PCR for quantitative detection of Mycoplasma genitalium DNA in males with and without urethritis who were attendees at a sexually transmitted disease clinic. J Clin Microbiol. 2004;42:683-92. https://doi.org/10.1128/JCM.42.2.683-692.2004

8. Deguchi T, Maeda S, Tamaki M, Yoshida T, Ishiko H, Ito M, et al. Analysis of the gyrA and parC genes of Mycoplasma genitalium detected in first-pass urine of men with 
non-gonococcal urethritis before and after fluoroquinolone treatment. J Antimicrob Chemother. 2001;48:742-4. https://doi.org/10.1093/jac/48.5.742

9. Murray GL, Bradshaw CS, Bissessor M, Danielewski J, Garland SM, Jensen JS, et al. Increasing macrolide and fluoroquinolone resistance in Mycoplasma genitalium. Emerg Infect Dis. 2017;23:809-12. https:/ / doi.org/10.3201/ eid2305.161745

10. Shimada Y, Deguchi T, Nakane K, Masue T, Yasuda M, Yokoi S, et al. Emergence of clinical strains of Mycoplasma genitalium harbouring alterations in parC associated with fluoroquinolone resistance. Int J Antimicrob Agents. 2010; 36:255-8. https:/ / doi.org/10.1016/j.ijantimicag. 2010.05.011

11. Hamasuna R, Le PT, Kutsuna S, Furubayashi K, Matsumoto M, Ohmagari N, et al. Mutations in $\operatorname{parC}$ and gyrA of moxifloxacin-resistant and susceptible Mycoplasma genitalium strains. PLoS One. 2018;13:e0198355. https://doi.org/10.1371/journal.pone.0198355

12. Dumke R, Thürmer A, Jacobs E. Emergence of Mycoplasma genitalium strains showing mutations associated with macrolide and fluoroquinolone resistance in the region
Dresden, Germany. Diagn Microbiol Infect Dis. 2016;86:2213. https:// doi.org/10.1016/j.diagmicrobio.2016.07.005

13. Golden MR, Workowski KA, Bolan G. Developing a Public Health Response to Mycoplasma genitalium. J Infect Dis. 2017;216(suppl_2):S420-6. https:/ / doi.org/10.1093/infdis/ jix200

14. Read TRH, Jensen JS, Fairley CK, Grant M, Danielewski JA, $\mathrm{Su}$ J, et al. Use of pristinamycin for macrolide-resistant Mycoplasma genitalium infection. Emerg Infect Dis. 2018;24:328-35. https://doi.org/10.3201/eid2402.170902

15. Bébéar CM, Grau O, Charron A, Renaudin H, Gruson D, Bébéar C. Cloning and nucleotide sequence of the DNA gyrase (gyrA) gene from Mycoplasma hominis and characterization of quinolone-resistant mutants selected in vitro with trovafloxacin. Antimicrob Agents Chemother. 2000;44:2719-27. https:// doi.org/10.1128/AAC.44.10.27192727.2000

Address for correspondence: Indira Basu, Auckland District Health Board, Private Bag 110031, Auckland Hospital, Auckland 1148, New Zealand; email IndiraB@adhb.govt.nz

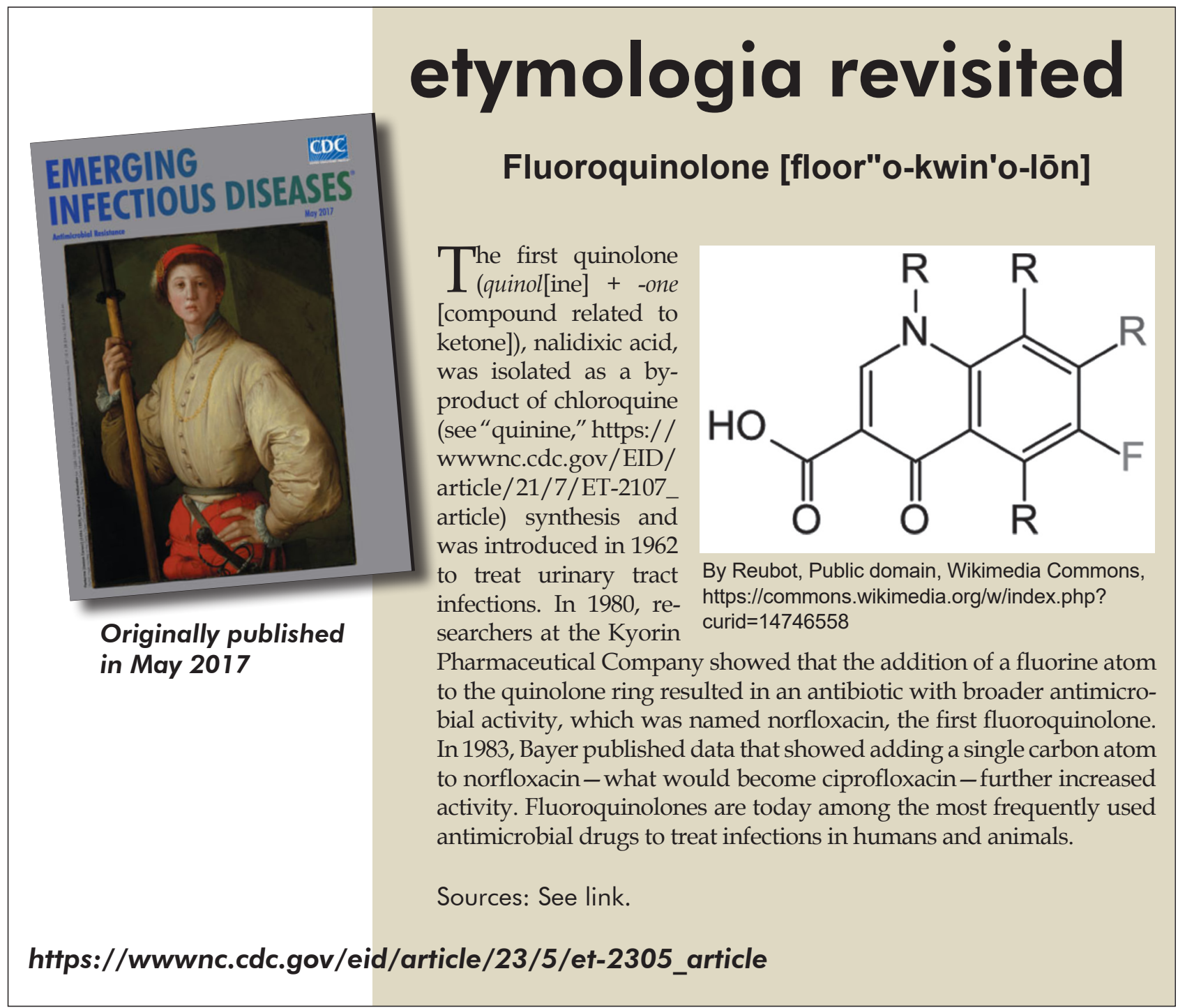

